the cumulative rate at first but at the end a not statistically significant $8 \%$ higher incidence in the former invited group. In other trials almost no excess incidence was shown when the control group was invited, which is to be interpreted as similar rates of over-diagnosis in both groups. ${ }^{14}$

\section{Exclusion of prevalent cases}

We found a reduced, but remaining, excess incidence after exclusion of prevalent cases (the first two screening rounds). This shows that the excess incidence is not just related to prevalent cases in a population exposed to screening. Two screening rounds correspond to four years, and the average lead time has been estimated to be two to four years depending on age. ${ }^{11}{ }^{12}$ Most of the prevalent cases in the invited group and their corresponding controls should therefore have been accounted for.

\section{Factors influencing over-diagnosis}

Attendance rates for screening decrease with age, as shown in both the Malmö mammographic screening trial and in the subsequent service screening programme. ${ }^{15}{ }^{16}$ On the other hand, women who had been screened in the Malmö trial were more likely to attend the service screening programme ${ }^{16}$ and probably also to undergo mammography after screening had ended. Furthermore, mammography of asymptomatic women outside the trial in the control groups may lead to underestimation of over-diagnosis.

It is widely agreed that screening using mammography can reduce mortality in breast cancer. The rate of over-diagnosis is another issue to be considered in the discussion on implications of breast cancer screening.

Contributors: See bmj.com.

Funding: None.

Competing interests: None declared.

Ethical approval: Ethical committee of Lund University.

1 Baines CJ. Are there downsides to mammography screening? Breast J 2005; 11:S7-10.

2 Duffy SW. Some current issues in breast cancer screening. J Med Screen 2005;12:128-33.

3 Day NE. Overdiagnosis and breast cancer screening. Breast Cancer Res 2005;7:228-9.

4 Paci E, Warwick J, Falini P, Duffy SW. Overdiagnosis in screening: is the increase in breast cancer incidence rates a cause for concern? J Med Screen 2004;11:23-7.

\section{What is already known on this topic}

Rates of over-diagnosis in screening for breast cancer have been estimated at $5 \%$ to $50 \%$

Evidence from randomised controlled trials is lacking

\section{What this study adds}

Over-diagnosis of breast cancer was $10 \%$ in women randomised to screening at age 55-69 years compared with an unscreened control group

Calculations are based on direct observations of follow-up 15 years after the end of a randomised controlled trial

5 Olsen AH, Jensen A, Njor SH, Villadsen E, Schwartz W, Vejborg I, et al. Breast cancer incidence after the start of mammography screening in Breast cancer incidence after the start
Denmark. Br J Cancer 2003;88:362-5.

6 Zahl PH, Strand BH, Maehlen J. Incidence of breast cancer in Norway and Sweden during introduction of nationwide screening: prospective cohort study. BMJ 2004;328:921-4.

7 Jonsson H, Johansson R, Lenner P. Increased incidence of invasive breast cancer after the introduction of service screening with mammography in Sweden. Int J Cancer 2005;117:842-7.

8 Andersson I, Aspegren K, Janzon L, Landberg T, Lindholm K, Linell F, et al. Mammographic screening and mortality from breast cancer: the Malmö mammographic screening trial. BMJ 1988;297:943-8.

9 Peeters PH, Verbeek AL, Straatman H, Holland R, Hendriks JH, Mravunac M, et al. Evaluation of overdiagnosis of breast cancer in screening with mammography: results of the Nijmegen programme. Int J Epide-

10 Duffy SW, Agbaje O, Tabár L, Vitak B, Bjurstam N, Bjorneld L, et al. Overdiagnosis and overtreatment of breast cancer: estimates of overdiagnosis from two trials of mammographic screening for breast cancer. Breast Cancer Res 2005;7:258-65.

11 Shapiro S, Goldberg JD, Hutchison GB. Lead time in breast cancer detection and implications for periodicity of screening. Am J Epidemiol 1974;100:357-66.

12 Moskowitz M. Breast cancer: age-specific growth rates and screening strategies. Radiology 1986;161:37-41.

13 Møller B, Weedon-Fekjaer H, Hakulinen T, Tryggvadottir L, Storm HH, Talbäck M, et al. The influence of mammographic screening on national Talbäck M, et al. The influence of mammographic screening on nation
trends in breast cancer incidence. Eur J Cancer Prev 2005;14:117-28.

14 Moss S. Overdiagnosis and overtreatment of breast cancer: overdiagnosis in randomised controlled trials of breast cancer screening. Breast Cancer Res 2005;7:230-4.

15 Matson S, Andersson I, Berglund G, Janzon L, Manjer J. Non-attendance in mammographic screening. A study of intra-urban differences from the city of Malmö in Sweden 1990-94. Cancer Detect Prev 2001;25:132-7.

16 Zackrisson S, Andersson I, Manjer J, Janzon L. Non-attendance in breast cancer screening is associated with unfavourable socio-economic circumstances and advanced carcinoma. Int J Cancer 2004;108:754-60.

(Accepted 27 January 2006)

doi $10.1136 /$ bmj.38764.572569.7C

\title{
Commentary: Over-diagnosis in breast cancer screening
}

Henrik Møller, Elizabeth Davies

The article by Zackrisson et al is an important follow-up study of diagnosis of breast cancer in women in the Malmö mammographic screening trial. ${ }^{1}$

In 2002 the International Agency for Research on Cancer concluded that population mammographic screening for women aged 50-69 years reduces the mortality from breast cancer by about one third. ${ }^{2}$ But screening can also lead to over-diagnosis and

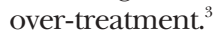

Over-diagnosis arises from two distinct phenomena: anticipation of diagnoses and excess diagnoses. Anticipation is the earlier diagnosis of cancers that would otherwise have become symptomatic and presented later: this phenomenon is both expected and desirable.
Excess diagnosis relates to cases detected through screening that would otherwise never have presented. A few may be false positive histological diagnoses, and some will arise when women are diagnosed by screening but then die shortly afterwards from other unrelated causes. Screening may also detect slow growing cancers that would not become symptomatic within the normal life expectancy.

When a new cohort of women first attends mammographic screening their incidence of breast cancer increases substantially compared with that of an unscreened cohort, owing to both anticipation and excess cases. During subsequent screens the incidence remains around $30 \%$ higher than before screening. 
Excess cases are more important here because anticipation will relate only to new tumours that have become detectable since the previous screen. Finally, when screening ceases at around age 64-69, the incidence returns to a lower than expected rate.

The most informative analysis in Zackrisson et al's study is the comparison of the cumulative incidence of breast cancer in the screened and the non-screened groups of women born between 1908 and 1922 and randomised between 1976 and 1978. ${ }^{1}$ This is a mature cohort with follow-up to 2001 when about $60 \%$ of the women had died. The main finding is a $10 \%$ increase in the lifetime occurrence of breast cancer (including cancer in situ) in the screened group.

The study's low statistical power precludes an exact estimate of over-diagnosis (95\% confidence limits around the $10 \%$ estimate are $1 \%$ and $18 \%$ ). Because some women randomised to screening were not screened and some women in the control group were, the intention to screen analysis leads to somewhat conservative estimates of over-diagnosis and of the reduction in breast cancer mortality (around 17\%).

To put these numbers into perspective, let us for simplicity assume that they are both correct. In a population where the lifetime risk of breast cancer is $8 \%$ and the lifetime risk of dying from breast cancer from age 50 onwards is $2.5 \%$, screening 250 women may prevent about one death from breast cancer. Screening would, however, also lead to the over-diagnosis of two cases. The woman whose death from breast cancer is prevented receives all the important benefit, whereas the two over-diagnosed women pay part of the price by becoming breast cancer patients and undergoing treatment. We cannot predict, however, which three women these will be.

The trouble is that although we can easily calculate these or alternative numbers based on different sets of data and assumptions, we cannot determine who the three women are. Ideally we should try to identify prognostic factors to distinguish the over-diagnosed cases and reduce the aggressiveness of their treatment. The first step towards this is to appreciate the reality of over-diagnosis and its likely magnitude. Zackrisson et al's study should inspire similar estimations of over-diagnosis in other populations, not only for breast cancer but also for colorectal cancer, prostate cancer, and other cancers, where organised screening or other diagnostic tests are being introduced.

Contributors: HM and ED jointly wrote the commentary. Funding: None.

Competing interests: None declared.

1 Zackrisson S, Andersson I, Janzon L, Manjer J, Garne JP. Rate of over-diagnosis of breast cancer 15 years after end of Malmô mammographic screening trial: follow-up study $B M J$ 2006:332:689-91.

International Agency for Research on Cancer. IARC handbooks of cancer prevention. Breast cancer screening. Lyon, France: IARC Press, 2009

Duffy SW. Some current issues in breast cancer screening. J Med Screen Duffy SW. Some

Moller B, Weedon-Fekjaer H, Hakulinen T, Tryggvadottir L, Storm HH, Moller B, Weedon-Fekjaer H, Hakulinen T, Tryggvadottir L, Storm HH,
Talback M, et al. The influence of mammographic screening on national trends in breast cancer incidence. Eur J Cancer Prev 2005;14:117-28.

doi 10.1136/bmj.38768.401030.7C
Bradford Dementia Group, Division of Dementia Studies, School of Health Studies, University of Bradford Bradford BD5 OBB Murna Downs professor in dementia studies

Dental Health Services Research Unit, Dundee University, Dundee Stephen Turner senior researcher continued over

\section{Effectiveness of educational interventions in improving detection and management of dementia in primary care: cluster randomised controlled study}

Murna Downs, Stephen Turner, Michelle Bryans, Jane Wilcock, John Keady, Enid Levin, Ronan O’Carroll, Kate Howie, Steve Iliffe showed evidence of improved concordance with guidelines regarding diagnosis and management of dementia.

Results Decision support software $(\mathrm{P}=0.01)$ and practice based workshops $(\mathrm{P}=0.01)$ both significantly improved rates of detection compared with control. There were no significant differences by intervention in the measures of concordance with guidelines. Conclusions Decision support systems and practice based workshops are effective educational approaches in improving detection rates in dementia.

\section{Introduction}

Inadequate detection of dementia in primary care and poor management have been documented nationally and internationally. People with dementia and their dementia and the extent to which medical records 